\title{
Re-evaluation of species diversity patterns of free-living marine nematodes
}

\author{
V. Mokievsky ${ }^{1, *}$, A. Azovsky ${ }^{2}$ \\ ${ }^{1}$ P. P. Shirshov Institute of Oceanology RAS, Moscow, Russia \\ ${ }^{2}$ Moscow State University, Faculty of Biology, Moscow, Russia
}

\begin{abstract}
Nematode species diversity was analysed for 55 data points ranging from local studies to large-scale faunal surveys. Multiple regression analysis uses latitude, investigated area, sampling effort and depth as independent variables. Species diversity in a biotope (or $\alpha$-diversity) is about twice as high in the deep sea, while the main source of diversity in shallow waters is heterogeneity of biotopes ( $\beta$-diversity). For sites deeper than $100 \mathrm{~m}$, regional species richness shows a unimodal (hump-shaped) latitudinal pattern, with the highest diversity at $30^{\circ}$ to $60^{\circ} \mathrm{N}$. Species diversity in shallow waters does not show any prominent gradients throughout the world ocean. These patterns possibly reflect the diversity-productivity relationships. Different approaches to estimation of species diversity are discussed.
\end{abstract}

KEY WORDS: Species diversity $\cdot$ Latitudinal gradients $\cdot$ Marine benthos $\cdot$ Nematodes Resale or republication not permitted without written consent of the publisher

\section{INTRODUCTION}

Global patterns in biodiversity, including latitudinal species diversity gradients (LSDGs: polarward declines in the number of species), are among the most exciting topics for modern ecology (Rosenzweig 1995, Huston 1999). LSDGs are known for many terrestrial and aquatic biotas, although the underlying causes are still disputable. However, marine meiofauna remains insufficiently explored in this respect.

Boucher (1990) investigated the diversity of shallowwater nematodes and discovered that tropical samples were less diverse than temperate ones. Lambshead (1993) and Boucher \& Lambshead (1995) repeated the analysis, grouping the biotopes according to depth and latitude. In shallow waters, tropical samples were not more diverse than temperate samples, while showing a wider range of diversity scatter. They also found the abyssal and bathyal samples to be more diverse than shallower ones. Recently, Lambshead et al. (2000, 2001) also reported a positive gradient for deep North

*E-mail: vom@soil.msu.ru
Atlantic nematodes between 13 and $56^{\circ} \mathrm{N}$. They related this pattern to the productivity gradient in the food-starved deep waters, although Rex et al. (2001) call these results into question, assigning a more important role to depth. Lambshead (1993) also used these data to estimate the potential total diversity of nematodes.

The critical point in looking for diversity patterns is the choice of an appropriate spatial scale (Huston 1999, Lawton 1999, Gray 2000). In the studies cited above, Boucher, Lambshead and their co-authors operate with local, or $\alpha$-diversity, which refers to only single sample data and ignores any point-to-point variations in species composition ( $\beta$-diversity). Thus, local (sample) diversity was used as the base for searching for global patterns. However, there is an obvious difference between local diversity (affected mainly by small-scale factors and processes) and regional ( $\gamma$-diversity) patterns, which are governed by large-scale processes and thus are the subject of macroecology. Therefore, regional data operating with summarised species lists are often considered to be more appropriate for searching out large-scale patterns (Lawton 1999). The main problem here is the absence of fully adequate 
data to investigate the broad-scale regional diversity of meiobenthos (Lambshead 1993, Lambshead et al. 2000). Nevertheless, as the latter authors fairly stated, 'It seems worthwhile to attempt to test for latitudinal gradients with the data we have while bearing in mind their problems' (Lambshead et al. 2000, p. 161).

We reconsider the available data on both local and regional species richness to evaluate separately the effects of sample size, depth and latitude. The main question is, do nematodes show a latitudinal gradient of diversity and, if so, what does it look like?

\section{MATERIALS AND METHODS}

Local data. We have used the world-wide data on local species richness for single samples or stations. Care was taken to employ data that were reasonably compatible in both sampling and taxonomic terms. For example, only data obtained from core samples and sieved using appropriate mesh size $(\leq 50 \mu \mathrm{m})$ were used, for which the original number of species and specimens were reported or could be recalculated. Three data sets were employed: (1) the deep-sea data presented by Lambshead (1993), Soetaert et al. (1995) and Lambshead et al. (2000) (29 values from 11 localities); (2) shallow-water data (littoral and sublittoral) from sources compiled by Boucher (1990) (99 values from 19 localities); and (3) additional shallow-water data compiled from Warwick \& Gee (1984), Heip et al. (1988), Austen \& Warwick (1989), Soetaert et al. (1995) and Steyaert et al. (1999) (43 values from 9 localities).

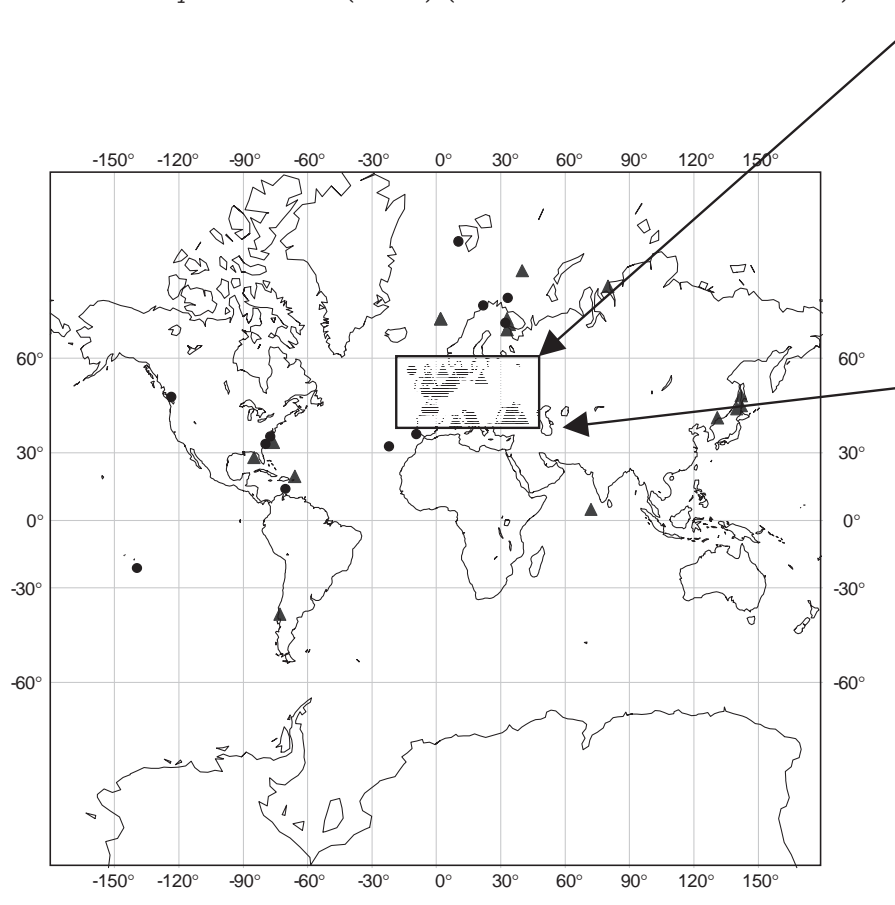

Scale: $1: 220000000$ at Latitude $0^{\circ}$
The numbers of species and specimens were transformed logarithmically by base 10 .

Regional data. The primary data were compiled from the publications that give species counts from 60 different geographical units. All the data were arbitrarily subdivided into 3 groups according to the 'sampling effort', treated as a categorical variable combining the number of samples and investigated area: (1) small-scale studies: local studies based on the restricted number of samples $(<15)$ collected from an area up to several square kilometres; (2) medium-scale studies: 15 to 50 samples that provide a species number for any part of the sea (small bay, bight, etc.) at the spatial range 1 to $1000 \mathrm{~km}^{2}$; (3) regional surveys on species richness for a whole sea or its part (>50 samples covering an area of $1000 \mathrm{~km}^{2}$ or more).

Areas were roughly estimated for the region surveyed or the polygon covered by samples, accurate to half an order of magnitude. The data cases were distributed over the world ocean (Fig. 1); all but 3 were from the northern hemisphere. These 3 cases from the southern hemisphere do not seriously affect the results, but fit well to the common trends. Five variables were included in the analysis: $\mathrm{S}$, the number of species (log-transformed, dependent variable); LATID, the absolute value of latitude (in degrees); AREA, the total area covered by samples or the region surveyed (logtransformed); SEFF, the sampling effort, a 3-level cate-

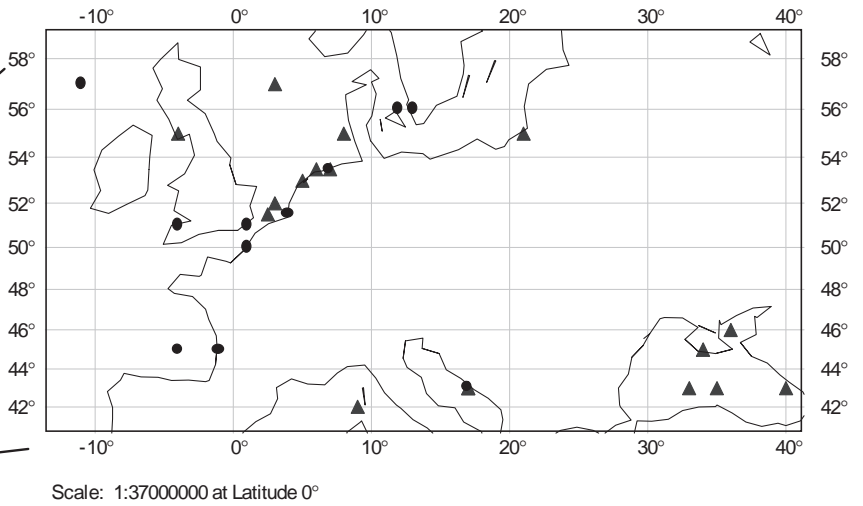

Fig. 1. Location of 'regional' data points provides the species lists of different sampling efforts (SEFF). ๑: $\mathrm{SEFF}=1$; A: $\mathrm{SEFF}=2$ or 3 
gorical variable (see above); and DEPTH, a categorical variable with 3 levels: 1, shallow (intertidal and upper subtidal) zone; 2 , shelf and upper slope (100 to $900 \mathrm{~m}$ depth); and 3, lower slope and abyssal plain zone deeper than $900 \mathrm{~m}$. The complete database for the analysis with references can be found on this journal's homepage (www.int-res.com/mokievsky-database.pdf).

For both local and regional data, we performed a fixed factor multivariate analysis of variance (MANOVA) and several variants of general linear regression modelling for unbalanced experimental designs (see 'Results') to test the effect of independent factors on species richness.

\section{RESULTS}

\section{Local diversity}

First, we examined 3 data sets - 1 deep-sea and 2 shallow (see above) - for sample-size dependence. As expected, the mean number of species per sample $(S)$ depended strongly on sample size $(N)$ for each set (Fig. 2). All regressions were consistently log-log linear, with the slopes non-significantly differing from each other. Moreover, the regressions for both shallow data sets practically coincide. This allows us to incorporate all the data into a single model for further analysis in the following form: $\log S=a+b \log N+c \log$ $\mathrm{DEPTH}+d$ LATID $+e$ LATID $^{2}$; where $a$ to $e$ are regression coefficients. We included the second-order term to account for possible non-linear effects of the latitude,
Table 1. Regression of local species richness (log S) on number of individuals $(\log N)$, depth and latitude (LATID). Multiple $\mathrm{R}^{2}=0.731$. SE: Standard error

\begin{tabular}{|lccccc|}
\hline Effect & Coefficient & SE & p (2-tailed) \\
\hline Log N & 0.498 & 0.031 & 0.000 \\
Log (depth) & 0.110 & 0.013 & 0.000 \\
LATID & 0.0013 & 0.0011 & 0.222 \\
LATID ${ }^{2}$ & -0.00001 & 0.00002 & 0.749 \\
ANOVA: & & & & & \\
Source & $\mathrm{SS}$ & $\mathrm{df}$ & $\mathrm{MS}$ & F-ratio & $\mathrm{p}$ \\
\hline Regression & 18.023 & 4 & 4.506 & 112.619 & 0.000 \\
Residual & 6.641 & & 166 & 0.040 & \\
\hline
\end{tabular}

such as intermediate peak in temperate waters. The results are given in Table 1 . The effect of sample size was highly significant, with an exponent value very close to 0.5 . This means that a 100 -fold increase of specimens counted yields a 10 -fold increase in species number. The effect of depth was also highly significant: abyssal or bathyal samples were, on average, almost twice as rich as equally sized shallow ones (Fig. 2). In contrast, latitude had no effect. After the effects of sample size and depth were removed, the residuals (deviations of the original species numbers from the 'species versus N+DEPTH' regression) showed no obvious patterns, except a rather weakly marked rise of deep-sea points in the temperate zone $\left(40\right.$ to $\left.60^{\circ} \mathrm{N}\right)$.
Fig. 2. Nematode diversity patterns for 'local' data sets. The number of species is plotted against the number of individuals in the samples at that site. Deep: Deep-sea data (slope: 0.465 \pm 0.066); Shallow-1: Data from Boucher (1990) (slope: $0.489 \pm 0.075$ ); Shallow-2: Additional shallow-water data (slope: $0.479 \pm 0.044$ )

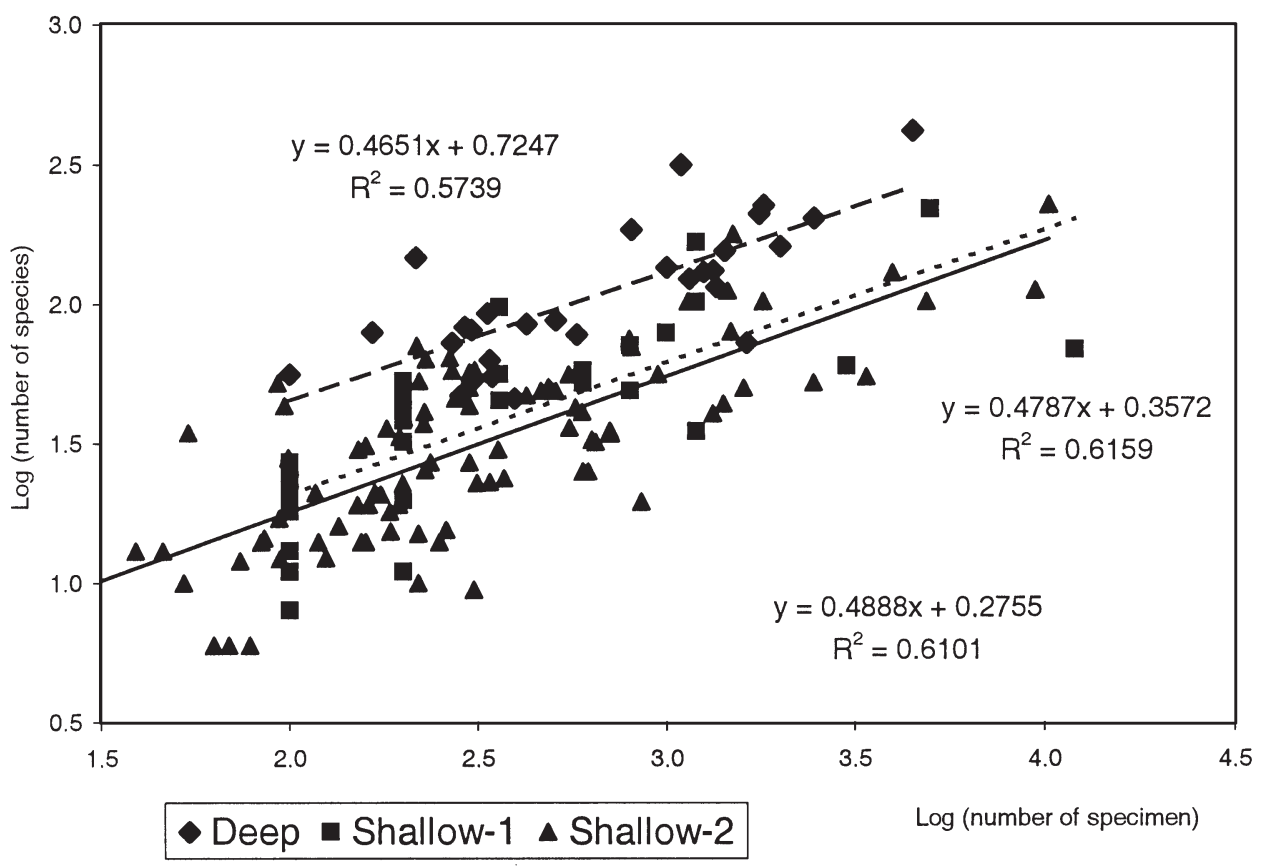


Table 2. Regression of regional species richness (log $\mathrm{S}$ ) on area, sampling effort (SEFF), depth and latitude. Multiple

$$
\mathrm{R}^{2}=0.608
$$

\begin{tabular}{|c|c|c|c|c|c|}
\hline Source & SS & $\mathrm{df}$ & $\begin{array}{c}\text { ANOVA } \\
\text { MS }\end{array}$ & $F$-ratio & $\mathrm{p}$ \\
\hline AREA & 0.284 & 1 & 0.284 & 8.077 & 0.006 \\
\hline SEFF & 0.199 & 2 & 0.099 & 2.832 & 0.068 \\
\hline DEPTH & 0.186 & 2 & 0.093 & 2.649 & 0.080 \\
\hline LATID & 0.082 & 1 & 0.082 & 2.340 & 0.132 \\
\hline LATID $^{2}$ & 0.154 & 1 & 0.154 & 4.373 & 0.041 \\
\hline Error & 1.827 & 52 & 0.035 & & \\
\hline
\end{tabular}

\section{Regional diversity}

From the beginning, we tested the mixed-effect linear model with all 5 variables (AREA, SEFF, DEPTH, LATID and LATID $^{2}$ ), including the quadratic latitudinal term to take into account possible non-linearity. Area and second-order latitudinal terms turned out to be the only significant variables; at the same time, the influence of sampling effort and depth were also noticeable (Table 2). In addition, the total variance had high between-block inhomogeneity, indicating possible interactions between variables (e.g. different depth dependence for local and regional subsets). However, our data were too limited and unbalanced to try more complicated models with interaction terms. Therefore, we used the procedure of stepwise removal of effects and adjusted residuals analysis (Draper \& Smith 1981). First, we estimated the species-area relation in its canonical form, $S=a \times$ AREA $^{\mathrm{z}}$, which explained up to $46 \%$ of the total variance (Fig. 3). Note that the slope value $(z=$ $0.092 \pm 0.015)$ turned out to be rather close to those obtained earlier for Arctic nematodes (Azovsky 2000).

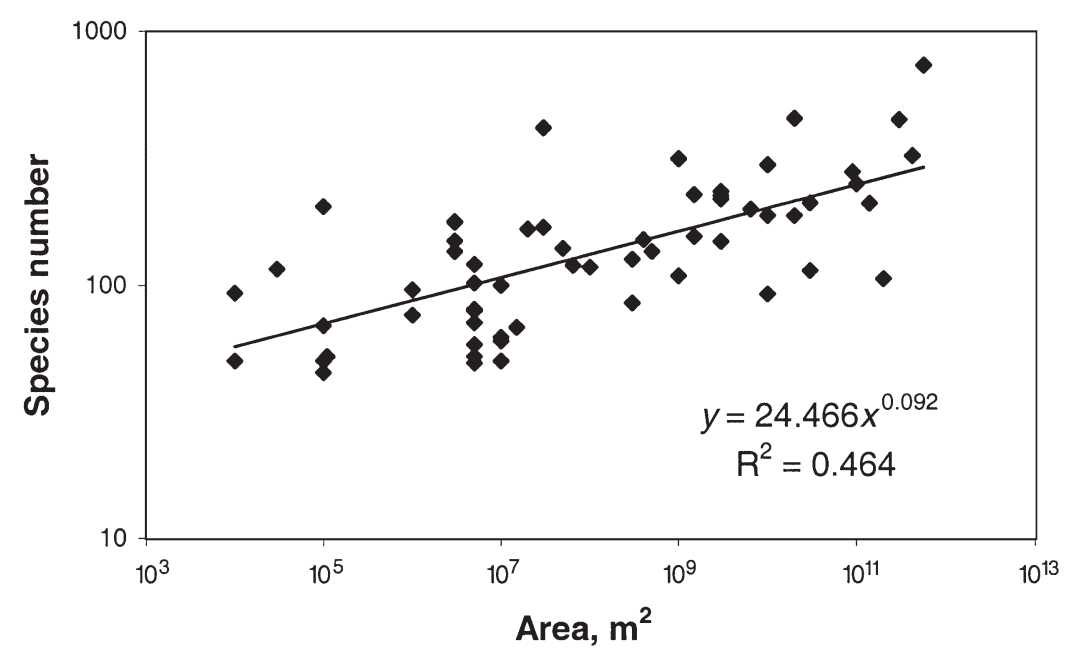

Fig. 3. Regional nematode diversity plotted against area
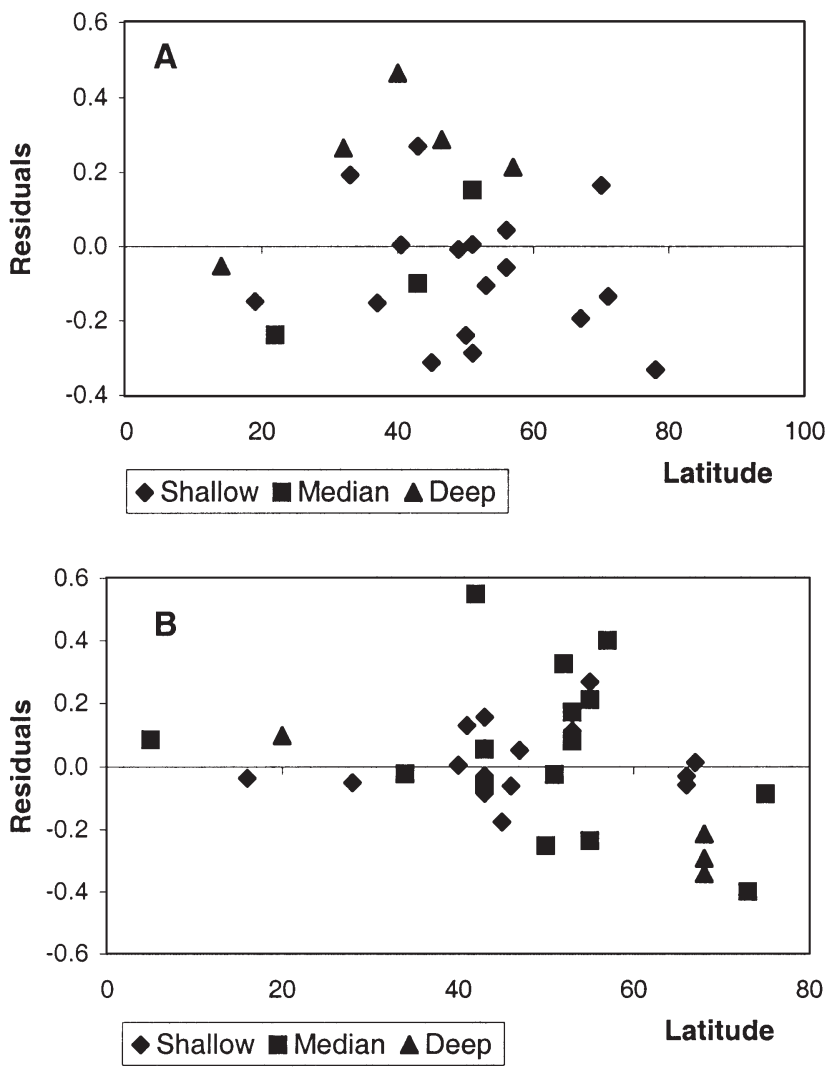

Fig. 4. Regional diversity residuals (after removing the area effect) plotted against latitude. (A) Small-scale data; (B) largescale data

For further detailed analysis, the area effect was removed from the data. The residuals were then examined separately for various sampling efforts. For the small-scale data (SEFF = 1), there was no noticeable latitudinal effect (Fig. 4A). However, the adjusted residual means for various depths differed significantly (Fig. 5A). As was the case for the local data, sites deeper than $900 \mathrm{~m}$ were on average twice as diverse as the shallow ones. For largescale data ( $\mathrm{SEFF}=2$ or 3 ), the situation was quite the reverse: the deepest regions had on average somewhat fewer species than shallower ones (Fig. 5B). At the same time, there was some latitudinal pattern, with a slightly pronounced increase in species richness in the temperate zone (Fig. 4B).

Next, the effects of both depth and sampling effort were also removed from the data, and the new adjusted residuals were then analysed for the influence of the latitude. Again, the 

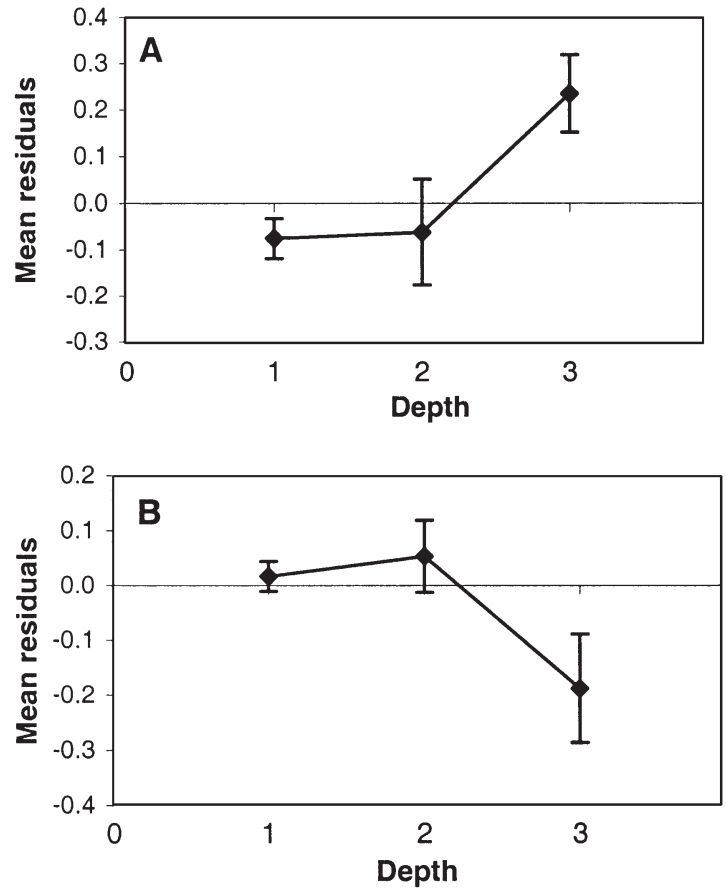

Fig. 5. Adjusted mean residuals (after removing area effect) for different depths $(1:<100 \mathrm{~m} ; 2: 100-900 \mathrm{~m} ; 3$ : >900 m). Bars show the standard deviations. (A) Small-scale data; (B) largescale data

results turned out to be different for different data subsets. In shallow waters, there were no latitudinal trends (Fig. 6A). For depths more than $100 \mathrm{~m}$, the diversity adjusted for depth and sampling effort changed non-linearly with latitude, with an obvious 'hump' in the temperate zone $\left(30\right.$ to $\left.60^{\circ} \mathrm{N}\right)$ and decreases to both poles and the tropics (Fig. 6B; multiple $\mathrm{R}=0.560$ is significant at the $1 \%$ level). For the deepsea data only, this pattern became still more evident (Fig. 6C).

\section{DISCUSSION}

One possible weak point of our analysis is combining the data from different oceans and seas (Fig. 1). The particular environments of these regions could affect diversity and confound a simple biogeographic pattern. Unfortunately, the data available to date are too incomplete for detailed analysis by different oceans separately (e.g. Atlantic vs Pacific). We demonstrate with North Atlantic data that restriction of the geographical range considered could also result in misinterpretation of the pattern. As new information will be gathered, such complementary analysis should be done further. As a compromise, we have checked our regressions for the longitudinal effects and tested all the adjusted data for the differences between Atlantic, Pacific and Indo-Pacific subsets. Neither longitudinal trends nor significant regional distinctions were found.

\section{Diversity patterns: scale, depth and latitude}

Both local and regional analyses gave, in general, similar results. As would be expected, the number of species was found to be strongly dependent on the sampling effort variables (number of individuals for
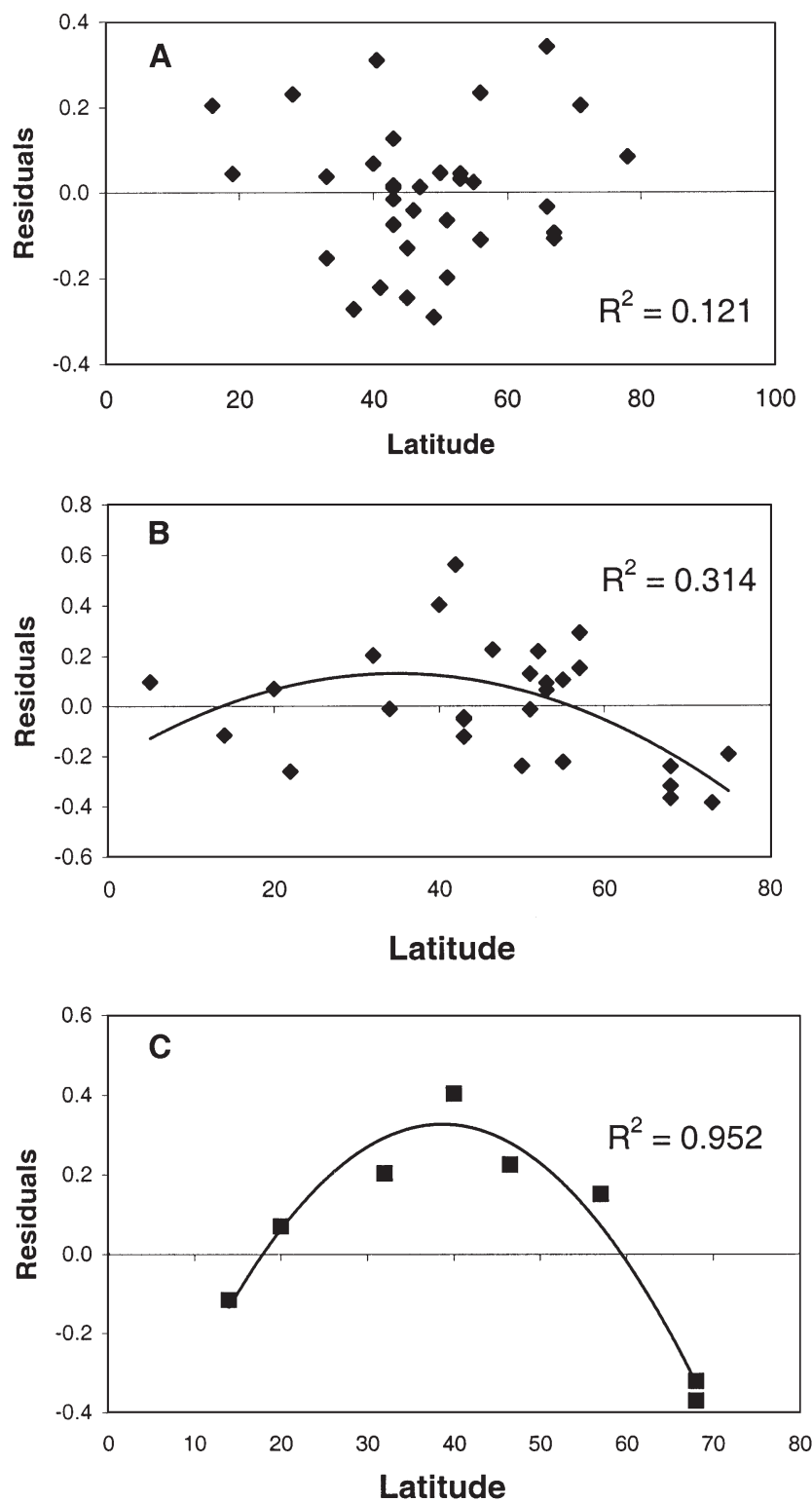

Fig. 6. Residuals (after removing the effects of area, depth and sampling effort) plotted against latitude. (A) Shallow-water sites; (B) sites deeper than $100 \mathrm{~m}_{i}$ (C) sites deeper than $900 \mathrm{~m}$ 
the local data or sampled area for regional data). After removal of these effects, both data sets showed relatively higher local but lower regional diversity in the deep-sea samples than in shallow waters. The higher local diversity in the bathyal and abyssal biotopes was also demonstrated earlier by Boucher \& Lambshead (1995). This may be treated as the argument of relatively low $\alpha$ - but high $\beta$-diversity in shallow waters. In other words, the main source of nematode diversity there occurs in small scale due to high within-biotope heterogeneity. It contrasts with the pattern suggested by Gray $(1994,2000)$ for macrofauna. The possible reasons for such a contrast have been specially discussed (Azovsky 2000, 2002).

Latitudinal patterns also changed drastically with depth, from lack of any trends in the littoral and upper sublittoral zone, to a hump-shaped distribution at the sites deeper than $100 \mathrm{~m}$, which was more obvious for localities deeper than $900 \mathrm{~m}$, with a peak at 45 to $50^{\circ} \mathrm{N}$. This result seemingly contradicts the positive linear trend proposed for North Atlantic deep-sea nematodes by Lambshead et al. (2000). In fact, their data also show a marked curvilinearity with a peak around 45 to $50^{\circ}$ (see op. cit. Fig. 3). These data were rather limited for the polar region with a single datum point north of $65^{\circ}$ (Norwegian Sea), which was excluded from their general trend as 'clearly an outlier' that is 'noticeably different from other Atlantic basins' due to historical and ecological features (Lambshead et al. 2000, p. 64-165). Our data points north of $65^{\circ}$, however, include not only the Norwegian Sea, but also the White, Barents and Kara seas and Spitsbergen, and all 12 cases but 1 show reduced diversity (the only exception is the data for Langesund and Frierfjord; Heip et al. 1988). In their 'depth or latitude' discussion with Lambshead, Rex et al. (2001) suggested that, once sample size and depth effects were removed, diversity did not show any linear latitudinal pattern. In reply, Lambshead et al. (2001) reanalysed their data and claimed that latitude (again, given as a linear term only) had more explanatory power than depth, though it became insignificant after the depth adjustment. We should note that the non-linear model fits the data from Lambshead et al. (2000) (including the Norwegian Sea) quite well (Table 3). After adjusting the species number for sampling effort, there appears to be a highly significant non-linear effect of latitude but not of depth. Thus, the unimodal latitudinal model seems to fit the data for deep-sea nematodes better than the linear trend does, and the poleward decrease of their diversity should be treated as a general phenomenon rather than a 'local exception'. As for lack of any gradients in shallow waters, Boucher \& Lambshead (1995) also did not find any differences between tropical and temperate subtidal nematode diversity.
Table 3. Regression of North Atlantic deep-sea species richness adjusted for sampling effort (data from Lambshead et al. 2000). Multiple $R^{2}=0.549$

\begin{tabular}{|c|c|c|c|c|c|}
\hline \multirow[b]{2}{*}{ Source } & \multirow[b]{2}{*}{ SS } & \multirow[b]{2}{*}{ df } & \multirow{2}{*}{$\begin{array}{c}\text { ANOVA } \\
\text { MS }\end{array}$} & \multirow{2}{*}{$F$-ratio } & \multirow[b]{2}{*}{$\mathrm{p}$} \\
\hline & & & & & \\
\hline LATID & 0.048 & 1 & 0.048 & 6.338 & 0.027 \\
\hline LATID $\times$ LATID & 0.046 & 1 & 0.046 & 6.011 & 0.030 \\
\hline DEPTH & 0.000 & 1 & 0.000 & 0.000 & 0.984 \\
\hline DEPTH $\times$ Depth & 0.006 & 1 & 0.006 & 0.842 & 0.377 \\
\hline Error & 0.092 & 12 & 0.008 & & \\
\hline
\end{tabular}

\section{Reasons for diversity gradients: depth and latitude}

In reply to Lambshead et al. (2001), Rex et al. (2001) indicated that 'if nematodes do not have a latitudinal gradient in diversity, or have a positive gradient, this could be a very interesting result. Nematodes may respond to the deep-sea environment in a way that is fundamentally different from other organisms.' However, the lack of simple latitudinal gradients has been reported for several taxonomic groups, mainly of meiobenthic size: nematodes, turbellarians, harpacticoid and cyclopoid copepods, etc. (Martens \& Schockaert 1986, Gobin 1992, Reid 1992 and many others). In some cases the signs of non-linear response also occur. For example, the same geographical patterns occur for soil nematodes, with the highest species richness found in the temperate zone (Procter 1984).

The unimodal (hump-shaped) deep-sea latitudinal trend, with regional diversity decreasing from temperate zone both to the equator and to the pole, corresponds even better to the 'productivity/disturbance' hypothesis advocated by Lambshead et al. (2001). The more or less speculative assumption is that the observed curve in the deep sea should be a result of 2 interacting factors: the productivity rate itself, which is affected by seasonal instability. In the Atlantic, where most of the data came from, the primary production between 45 and $50^{\circ} \mathrm{N}$ is still high but the seasonal changes also become prominent. Due to the conspicuous small-scale variations in organic content, which extend over geographical differences in shallow waters, the absence of the same gradient in the last case also fits well with this explanation.

The hump-shaped response of diversity to productivity is well known for various taxa and ecosystem types, though its causes and mechanisms are still unclear (see reviews by Abrams 1995, Waide et al. 1999). Wollenburg \& Kuhnt (2000) show that the decrease in foraminifer diversity correlated well with the decrease of carbon flux in the high Arctic. On a larger scale, the highest diversity rates correspond to intermediate values of carbon flux (J. Wollenburg pers. comm.). It is 
well known in limnology that the highest species richness occurs in mesotrophic lakes (Ghilarov 2001). The same type of response was shown recently for such different groups as terrestrial vascular plants (Naeem et al. 1994, Hector et al. 1999) and bacteria (Kassen et al. 2000).

As Lambshead et al. (2001) recently proposed, 'Given our limited data, maybe it would be productive to analyse the patterns of different taxa against each other to test for differences between taxa' (p. 301). Indeed, Hillebrand \& Azovsky (2001) showed that latitudinal diversity patterns for various systematic groups - marine, freshwater and terrestrial-are regularly scaled to the average body size, from generally strong and evident negative gradients for the largest organisms to the lack of any monotonous gradient for the smallest ones, such as ciliates or microalgae. To explain this fact they assumed that communities of the smallest eukaryotes become established at finer spatio-temporal scales; therefore, their species richness is determined more by local ecological factors than by global processes. Nematodes, in this context, occupy an intermediate position between micro- and macroorganisms, so they are likely to be equally affected by both local and regional factors. Indeed, local diversity (measured either as number of species per sample or by rarefaction statistics) do not reveal any latitudinal (i.e. global) patterns (Boucher \& Lambshead 1995, Lambshead et al. 2000, Rex et al. 2001, and our data). In its turn, the regional diversity shows the distinct pattern in the deep zone only, where local heterogeneity accounting for the $\beta$-component of diversity is relatively low. So, at a regional scale, the local environmental factors proved to be more important in explaining species diversity than latitudinal (global) gradients.

\section{How many nematodes are in the ocean? Limits of extrapolation}

The local approach implies that the methods of $\alpha$ diversity estimation can be directly extrapolated across the scales right up to the global scope. Grassle \& coworkers' research of deep-sea macrofauna diversity (Grassle 1991, Grassle \& Maciolek 1992) is the most striking example. They detected new species at the rate of 1 per every kilometre investigated along their transect, and then they presumed this rate to hold out for every square kilometre of ocean floor. Simply multiplying it by the ocean area, they obtained $10^{8}$ macrofaunal species. Following this method (extrapolating the abundance-species number relationship to the whole ocean), we should also assume the 'magic' number of $10^{8}$ species for marine nematodes (Lambshead 1993).
The logic of this approach is as simple as it is doubtful: if one has found that nearly half the species in a sample have not been described, then (one believes) it will be so for every sample taken in every point anywhere. But it is obviously not so! What these data actually tell us is how poorly known these species are, not how many there are. Such a 'direct multiplication' method is 'statistical legerdemain' because the local estimations cannot be extended far beyond the scale of sampling (Briggs 1991, Azovsky 2002). Inadequacy of the approach could easily be demonstrated from our results. Extrapolating the above-described abundance-species number relation downward to 51 specimens, we obtain 24 to 47 (on average 33) species expected for deep-sea localities and 12 to 26 (on average 18) for shallow waters. These figures are rather close to the rarefaction estimates made by Lambshead (1993) and Boucher \& Lambshead (1995). But upward extrapolation to 261889 specimens (mean abundance per square metre reported for Rockall Trough) gives from 1000 to 2000 species $\mathrm{m}^{-2}$. Since nematodes are often more abundant (about 100 to 200 ind. $\mathrm{cm}^{-2}$; Heip \& Craeymeersch 1995, Vanaverbeke et al. 1997), we should expect there to be up to 3000 species $\mathrm{m}^{-2}$ - too much even for an extremely optimistic nematodologist!

On the other hand, extrapolation of the regional data from the species-area curves vastly underestimates the figures. The equation obtained above, for example, predicts as few as 700 to 900 species for the whole ocean area. The reason is evident: the present-day species lists for any more or less large regions are far from their real diversity (Lambshead 1993). So, we are faced with the dilemma: local data cannot be extended over the large spatial scales, but regional models cannot be built on the incomplete data. Certainly, the problem is far from a definitive resolution. One possible way could be the coupling of the approaches. We could use the local data to estimate the potential $\alpha$-diversity within relatively small plots (e.g. by species-specimens relations or rarefaction procedures). Then, these figures could be used as the starting point for extrapolating over a larger scale in models including the effects of area, biotope, historical-geographical processes and so on. The development of such models is still a long way in the future. Nevertheless, very rough calculations based on the above-described data give a total of approximately 10000 to 20000 species of marine nematodes. It is several times higher than those that have been described to date, but much lower than Lambshead's prediction. For Russian Arctic seas (371 species recorded to date), the estimated figure is 2000 to 4000 species. It is of the same order of magnitude as the 1300 species predicted recently on the basis of very different reasoning (Kulangieva \& Galtsova 1999). 
Acknowledgements. This work was supported by the Russian Fund for Basic Researches (grants no. 99-05-69369 and 00-0449175). The authors greatly appreciate the fruitful discussions on the paper's content with colleagues from the Deep-sea Research Group of the Alfred-Wegener Institute for Polar and Marine Researches (Bremerhaven). We would like to thank the MEPS reviewers for helpful criticism of the earlier manuscript version. Special thanks to Dr. Jonathan Rudge (Biodiversity Conservation Centre, Moscow) for improving the style of the paper.

\section{LITERATURE CITED}

Abrams P (1995) Monotonic or unimodal diversity-productivity gradients: what does competition theory predict? Ecology 76:2019-2027

Austen MC, Warwick RM (1989) Comparison of univariate and multivariate aspects of estuarine meiobenthic community structure. Estuar Coast Shelf Sci 29:23-42

Azovsky AI (2000) Concept of scale in marine ecology: linking the words or the worlds? Web Ecol 1:28-34. Available at: www.oikos.ekol.lu.se/we/WE2000.html

Azovsky AI (2002) Size-dependent species: area relationships in benthos: is the world more diverse for microbes? Ecography 25:273-282

Boucher G (1990) Pattern of nematode species diversity in temperate and tropical subtidal sediments. PSZN I: Mar Ecol 11:133-146

Boucher G, Lambshead PJD (1995) Ecological biodiversity of marine nematodes in samples from temperate, tropical, and deep-sea regions. Conserv Biol 9:1594-1604

Briggs JC (1991) Global species diversity. J Nat Hist 25: 1403-1406

Draper NR, Smith H (1981) Applied regression analysis. John Wiley \& Sons, New York

Ghilarov AM (2001) The relation between biodiversity and productivity: science and politics. Priroda (Moscow) 2: 20-24 (in Russian)

Gobin JF (1992) A comparison of meiofaunal species diversity from temperate and tropic localities. In: 8th Int Meiofauna Conf, 9-14 Aug 1992, University of Maryland, p 19

Grassle JF (1991) Deep-sea benthic biodiversity. Bioscience 41:464-469

Grassle JF, Maciolek NJ (1992) Deep-sea species richness: regional and local diversity estimates from quantitative bottom samples. Am Nat 139:313-341

Gray JS (1994) Is deep-sea species diversity really so high? Species diversity of the Norwegian continental shelf. Mar Ecol Prog Ser 112:205-209

Gray JS (2000) The measurement of marine species diversity, with an application to the benthic fauna of the Norwegian continental shelf. J Exp Mar Biol Ecol 250:23-49

Hector A, Schmidt B, Beierkuhnlein C, Caldeira MC and 30 others (1999) Plant diversity and productivity experiments in European grasslands. Science 286:1123-1127

Heip C, Craeymeersch JA (1995) Benthic community structures in the North Sea. Helgol Wiss Meersunters 49: 313-328

Heip C, Warwick RM, Carr MR, Herman PMJ, Huys R, Smol N, Van Holsbeke K (1988) Analysis of community attributes of the benthic meiofauna of Frierfjord/Langesundfjord. In: Bayne BL, Clarke KR, Gray JS (eds) Biological

Editorial responsibility: Otto Kinne (Editor), Oldendorf/Luhe, Germany effects of pollutants: results of a practical workshop. Mar Ecol Prog Ser 46:171-180

Hillebrand H, Azovsky AI (2001) Body size determines the strength of the latitudinal diversity gradient. Ecography 24:251-256

Huston MA (1999) Local processes and regional patterns: appropriate scales for understanding variation in the diversity of plants and animals. Oikos 86:393-401

Kassen R, Buckling A, Bell G, Rainey PB (2000) The species diversity of natural communities is often strongly related to their productivity. Nature 406:508-512

Kulangieva LV, Galtsova VV (1999) Nematode biodiversity of Russian Arctic seas. In: Problems of nematology. 3rd RSN Int Nematol Symp, St. Petersburg, p 52

Lambshead PJD (1993) Recent developments in marine benthic biodiversity research. Oceanis 19:5-24

Lambshead PJD, Tietjen J, Ferrero TJ, Jensen P (2000) Latitudinal diversity gradients in the deep-sea with special reference to North Atlantic nematodes. Mar Ecol Prog Ser 194:159-167

Lambshead PJD, Tietjen J, Moncrieff CB, Ferrero TJ (2001) North Atlantic latitudinal diversity patterns in deep-sea marine nematode data: a reply to Rex et al. Mar Ecol Prog Ser 210:299-301

Lawton JH (1999) Are there general laws in ecology? Oikos 84:177-192

Martens PM, Schockaert ER (1986) The importance of turbellarians in the marine meiobenthos: a review. Hydrobiologia 132:95-303

Naeem S, Lawler SP, Thompson LJ, Woodfin RM (1994) Declining biodiversity can alter the performance of ecosystems. Nature 368:734-737

Procter DLC (1984) Towards a biogeography of free-living soil nematodes. I. Changing species richness, diversity and densities with changing latitude. J Biogeogr 11:103-117

Reid JW (1992) Relative latitudinal diversity of continental cyclopoid and harpacticoid copepods of the Americas. In: 8th Int Meiofauna Conf, 9-14 Aug 1992, University of Maryland, p 18

Rex MA, Stuart CT, Etter RJ (2001) Do deep-sea nematodes show a positive latitudinal gradient of species diversity? The potential role of depth. Mar Ecol Prog Ser 210:297-298

Rosenzweig ML (1995) Species diversity in space and time. Cambridge University Press, Cambridge

Soetaert K, Vincx M, Wittoeck J, Tulkens M (1995) Meiobenthic distribution and nematode community structure in five European estuaries. Hydrobiologia 311:185-206

Steyaert M, Garner N, van Gansbeke D, Vincx M (1999) Nematode communities from the North Sea: environmental controls on species diversity and vertical distribution within the sediment. J Mar Biol Assoc UK 79:253-264

Vanaverbeke J, Soetaert K, Heip C, Vanreusel A (1997) The metazoan meiobenthos along the continental slope of the Goban Spur (NE Atlantic). J Sea Res 38:93-107

Waide RB, Willig MR, Steiner CF, Mittelbach G, Gough L, Dodson SI, Joday GP, Parmenter R (1999) The relationship between productivity and species richness. Annu Rev Ecol Syst 30:257-300

Warwick RM, Gee JM (1984) Community structure of estuarine meiobenthos. Mar Ecol Prog Ser 18:97-111

Wollenburg J, Kuhnt W (2000) The response of benthic foraminifers to carbon flux and primary production in the Arctic Ocean. Mar Micropaleontol 40:189-231

Submitted: May 22, 2001; Accepted: March 19, 2002

Proofs received from author(s): July 15, 2002 